\title{
A pharmacological model reveals biased dependency on PI3K isoforms for tumor cell growth
}

\author{
Xiang WANG\#, Jia-peng LI", Yan YANG, Jian DING* , Ling-hua MENG* \\ Division of Anti-Tumor Pharmacology, State Key Laboratory of Drug Research, Shanghai Institute of Materia Medica, Chinese Academy \\ of Sciences, Shanghai 201203, China
}

\begin{abstract}
Aim: To identify the contribution of individual isoform $(\alpha, \beta, \gamma, \delta)$ of class I PI3Ks to tumor cell growth for proper use of PI3K inhibitors in cancer therapy.

Methods: A panel of human rhabdomyosarcoma Rh30 cells stably expressing myristoylation (Myr)-tagged one of class I PI3K p110 subunits was established. PI3K activity was analyzed by measuring phosphorylated Akt with Western blotting, and isoform-specific $\mathrm{PI} 3 \mathrm{~K}$ activities were validated with PI3K isoform-selective inhibitors. The growth of prostate cancer PC-3 cells and B cell type leukemia Raji cells was determined using SRB assay and CCK-8 assay, respectively.

Results: The phosphorylation of Akt in Rh30-Myr-p110 $\alpha, \beta, \gamma, \delta$ cells was preferentially inhibited by PI3K isoform-selective inhibitors A66 (PI3K $\alpha)$, TGX221 (PI3Kß), AS604850 (PI3Ky) and CAL-101 (PI3Kס), respectively. A newly obtained PI3K inhibitor WJD008 (10 $\mu \mathrm{mol} / \mathrm{L})$ completely abrogated Akt phosphorylation by all the isoforms of class I PI3Ks, thus acted as a pan-PI3K inhibitor. In prostate cancer PC-3 cells, the PI3K isoform-selective inhibitors were much less potent than WJD008 in suppression of the proliferation. In B cell type leukemia Raji cells, inhibition of PI3K $\delta$ alone or all the isoforms of class I PI3Ks displayed similar potency against the cell proliferation, whereas selective inhibition of individual $\mathrm{PI} 3 \mathrm{~K} \alpha / \beta / \mathrm{Y}$ isoforms resulted in negligible activity.

Conclusion: Rh30-Myr-p110 $\alpha, \beta, \gamma, \delta$ cells are a useful cell model to identify the selectivity of PI3K inhibitors. Pan-PI3K inhibitors are suitable for treating PC-3 cells, whereas selective PI3Kס inhibitor is sufficient to block Raji cell growth. The biased dependency on PI3K isoforms for tumor cell growth rationalizes the use of PI3K inhibitors with different selectivity for cancer therapy.
\end{abstract}

Keywords: anticancer drug, PI3K inhibitor, drug selectivity; WJD008; prostate cancer; B cell type leukemia; screening model

Acta Pharmacologica Sinica (2013) 34: 1201-1207; doi: 10.1038/aps.2013.81; published online 29 Jul 2013

\section{Introduction}

The phosphatidylinositol 3-kinase (PI3K)-mediated signaling pathway plays a central role in a complex, multi-armed signaling network that orchestrates cell responses, including cell survival, growth, proliferation, angiogenesis, migration and glucose metabolism $^{[1]}$. PI3K are lipid kinases that phosphorylate 3-OH of phosphatidylinositol, which are divided into three classes according to their structural and substrate specificity (I, II, and III). Class I PI3Ks are further divided into class IA and class IB. The class IA isoforms PI3Ka, PI3K $\beta$, and PI3Kס are all bound to one of the p85/p55/p50 regulatory subunits, whereas PI3K $\gamma$, the only IB PI3K, associates with the adaptor proteins $\mathrm{p} 101$ or p87 ${ }^{\text {PIKAP [2] }}$. Class I PI3K isoforms localize and function non-redundantly in cells; PI3Ka and PI3K $\beta$ are ubiquitously expressed and regulate insulin signaling, neovascu-

\footnotetext{
\# These authors contributed equally to this work.

* To whom correspondence should be addressed.

E-mail Ihmeng@mail.shcnc.ac.cn (Ling-hua MENG); suozhang@mail.shcnc.ac.cn (Jian DING)

Received 2013-04-19 Accepted 2013-05-16
}

larization and platelet aggregation, whereas PI3K $\delta$ and $\mathrm{PI} 3 \mathrm{~K} \gamma$ are mainly expressed in leukocytes and regulate immune processes $^{[3-5]}$.

PI3K-mediated signaling network is important in tumorigenesis and progression, which is frequently hyper-activated in a variety of human cancers. This is a result of either gain-offunction in PI3K, inactivation of the lipid phosphatase PTEN (phosphatase and tensin homolog) or deregulated growth factor signaling ${ }^{[6,7]}$. PI3K has been validated as a therapeutic tumor target of increasing interest from the research community of tumor biology and cancer therapeutics as well ${ }^{[8,9]}$. Due to efforts in academia and industry to develop clinically relevant inhibitors, a number of pan- or isoform-specific PI3K inhibitors have been identified and developed as potential molecularly targeted anticancer therapies, including GDC0941 (pan-PI3K), A66 (PI3Ka), TGX221 (PI3K $\beta$ ), AS604850 (PI3Kү), and CAL-101 (PI3Kס $)^{[6,10-14]}$. Isoform inhibitors may enhance targeting and reduce toxicity, whereas pan-PI3K inhibitors are thought to be more potent with wide antitumor spectrum. Therefore, understanding the specificity of PI3K inhibitors 
within cells is important for their proper use. Most isoformselectivity data of the present inhibitors were obtained from biochemical assays, due to a lack of reliable cellular systems to identify their selectivity ${ }^{[15]}$. In addition, the contribution of each isoform within given cells for growth is not fully understood and isoform-selective PI3K inhibitors are good tools for such study. For example, PI3Ka inhibitors were considered to possess antitumor activity against PIK3CA mutated tumors ${ }^{[6]}$, PI3K $\beta$ was the potential target in PTEN negative cancers ${ }^{[16]}$, and $\mathrm{PI} 3 \mathrm{~K}_{\gamma}$ and $\mathrm{PI} 3 \mathrm{~K} \delta$ were important promoters for $\mathrm{T}$ cell acute lymphocytic leukemia and B cell type chronic lymphocytic leukemia ${ }^{[17-19]}$.

In the present study, we strived to establish a cell model to identify the specificity of PI3K inhibitors with an isogenic background and unified readout and then the identified inhibitors were used as probes to determine the contribution of each isoforms to cell growth in specific cell type and in turn to clarify the antitumor potential of these inhibitors.

\section{Materials and methods}

\section{Compounds and plasmids}

A66, CAL-101 (Selleck Chemicals, Houston, TX, USA), AS604850 (Cayman Chemical Company, Ann Arbor, MI, USA) and WJD008 (synthesized in house with over 98\% purity) were dissolved in dimethyl sulfoxide at $10 \mathrm{mmol} / \mathrm{L}$ and stored at $-20^{\circ} \mathrm{C}$. TGX221 (Cayman Chemical Company, Ann Arbor, MI, USA) was provided in alcohol at $1 \mathrm{mg} / \mathrm{mL}$. Plasmids containing p110a or $\mathrm{p} 110 \beta$ were kindly provided by Thomas ROBERTS (Harvard Medical School), and plasmids containing $\mathrm{p} 110 \mathrm{y}$ or $\mathrm{p} 110 \delta$ were kindly provided by Peter K VOGT (The Scripps Research Institute). pBABE-puro plasmid was acquired from Addgene (Addgene plasmid 1764); pGP and pE-Ampho plasmids were purchased from Takara (Dalian, China).

\section{Cell culture}

A human rhabdomyosarcoma Rh30 cell line was a gift from the St Jude Children's Research Hospital (Memphis, TN, USA). The parental and transfected Rh30 cells were maintained in RPMI-1640 medium supplemented with 10\% fetal bovine serum (FBS). Human prostate cancer PC-3 cells and B cell type leukemia Raji cells were obtained from the American Type Culture Collection and were cultured in F-12 or RPMI -1640 medium supplemented with 10\% FBS. 293FT cells were purchased from Life Technologies Corporation (Carlsbad, CA, USA) and maintained in DMEM plus 10\% FBS.

\section{Cell transfection}

Myristoylated tag (ATGGGGTCTTCAAAATCTAAACCAAAGGACCCCAGCCAGCGCCGGCGCAGAATCCGAGGT) and HA tag (TACCCATACGACGTGCCAGATTACGCCGGA) were ligated in tandem with each p110 gene sequences and then inserted into pBabe-Puro plasmid. The resulting constructs were co-transfected with pGP and pE-Ampho plasmids into 293FT cells to obtain retrovirus, which were then used to infect Rh30 cells. After selection with $1 \mu \mathrm{g} / \mathrm{mL}$ puromycin for
1 week, cells stably expressing myristoylated PI3K isoforms were pooled for validation and named as Rh30-Myr-p110a, Rh30-Myr-p110ß, Rh30-Myr-p110y, and Rh30-Myr-p1106, accordingly.

\section{Western blot analysis}

Rh30-Myr-p110 cells grown to 50\% confluence in 12-well plates continued to be incubated in serum-free medium for $12 \mathrm{~h}$ and were then exposed to tested compounds at indicated concentrations for $1 \mathrm{~h}$. The cells were collected and lysed in $1 \times$ SDS-loading buffer [50 mmol/L Tris-HCl (pH 8.0), 2\% SDS, $100 \mathrm{mmol} / \mathrm{L}$ DTT, $0.001 \%$ bromophenol blue, 10\% glycerol] and were heated at $95^{\circ} \mathrm{C}$ for $10 \mathrm{~min}$. Standard Western blot was proceeded with the antibodies against Akt, Akt pT308, Akt pS473 (Cell Signaling Technology, Danvers, MA, USA) and $\beta$-actin (Sigma Aldrich, St Louis, MO, USA). Relative grey intensity of bands was analyzed with ImageQuant TL software (GE Healthcare Life Sciences, Piscataway, NJ, USA).

\section{Cell proliferation assays}

Proliferation of PC-3 cells was evaluated by sulforhodamine B (SRB) assay as previously reported ${ }^{[20]}$. Viability of Raji cells was assessed using a cell counting kit (CCK-8, Ddojindo, Japan) following the manufacturer's protocol. Briefly, cells seeded in a 96-well plate were settled for $6 \mathrm{~h}$ before diluted compounds were added to each well at desired concentrations in triplicate. CCK- 8 reagent was added $72 \mathrm{~h}$ later followed by color development to the appropriate density and the $O D$ value was measured at $450 \mathrm{~nm}$. The inhibitory rate was calculated using the formula: $\left(O D_{\text {control cells }}-O D_{\text {treated cells }}\right) /$ $O D_{\text {control cells }} \times 100 \%$.

\section{Statistical analysis}

Data was shown as mean $\pm S D$ (standard deviation) of at least 3 independent experiments. A value of $P<0.05$ was considered statistically significant.

\section{Results}

Myristoylation-tagged PI3K catalytic subunits possessed stimuliindependent kinase activity

To test the specificity of PI3K inhibitors in cellular system, we generated a panel of human rhabdomyosarcoma Rh30 cell lines that stably expressed one myristoylation (Myr)-tagged p110 catalytic subunit (p110a, p110 $\beta$, p110y, or p1106, respectively) of human class I PI3K at the N terminal, namely Rh30Myr-p110a, Rh30-Myr-p110ß, Rh30-Myr-p110y, or Rh30-Myrp110ठ (Figure 1A). We next assessed the protein levels of each p110 isoform by detecting HA-tag. As shown in Figure 1B, HA was detectable in all 4 p110 but not vector expressing cells, indicating expression exogenous p110 isoforms in these cells. p110 $\gamma$ and $\mathrm{p} 110 \delta$ were expressed more efficiently than p110a or p110 $\beta$ in the cell lines. The ectopically expressed p110 isoforms are supposed to be membrane-anchoraged and constitutively active due to myristoylation at N-terminals. We detected phosphorylated Akt as a readout of PI3K activity. As shown in Figure 1C, Akt was phosphorylated in the presence 
A

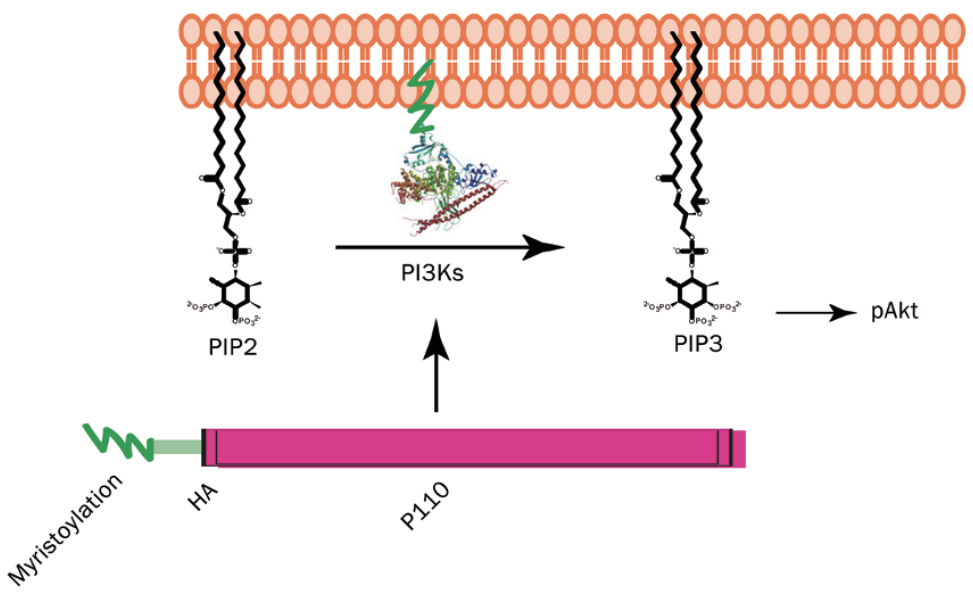

B

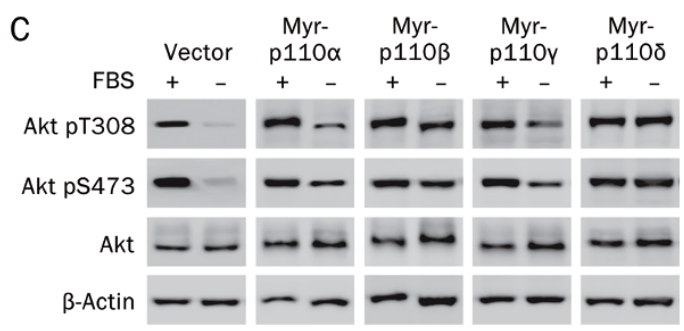

Figure 1. Establishment of PI3K isoform-expressing Rh30 cells. (A) Scheme of the steps: Plasmids that encode myristoylation-HA-p110 were transfected into Rh30 cells by retrovirus. The ectopic proteins are membrane-targeted and constitutively produce second messenger PIP3, which results in phosphorylation of Akt. (B) Western blots were performed to detect each p110s expression indicated by HA-tag. (C) Myr-p110- or control vector-transfected Rh30 cells were cultured either in presence of (FBS+) or absence of FBS (FBS-) for $12 \mathrm{~h}$, then phosphorylation of Akt at Thr308 and Ser473 was detected. $\beta$-Actin was served as loading control. Representative images are presented.

of FBS throughout all cells tested, whereas constitutively phosphorylated Akt was observed in cells expressing the myristoylated p110 isoforms but not in the control vector-transfected counterpart under the serum-free condition.

\section{Isoform-selective PI3K inhibitors blocked PI3K signaling in corresponding Rh30-Myr-p110 cells}

To test whether the newly established Rh30-Myr-p110 cells could be used to identify the isoform selectivity of PI3K inhibitors, we treated the panel of cells with reported PI3Ka inhibitor A66, PI3K $\beta$ inhibitor TGX221, PI3Kץ inhibitor AS604850 or PI3K $\delta$ inhibitor CAL-101 under serum-free conditions and then detected the level of phosphorylated Akt (Figure 2). A66 was reported as a highly selective PI3Ka inhibitor with $\mathrm{IC}_{50}$ of $32 \mathrm{nmol} / \mathrm{L}$ in biochemical assays, displaying more than 100 -fold selectivity over other class I PI3K isoforms ${ }^{[6]}$. We found that A66 significantly inhibited the phosphorylation of Akt in Rh30-Myr-p110a cells at the concentration of $100 \mathrm{nmol} /$ $\mathrm{L}$, but more than $3 \mu \mathrm{mol} / \mathrm{L}$ was required to inhibit Akt phosphorylation to the same extent in Rh30-Myr-p110y cells. Additionally, it had almost no inhibitory effect in Rh30-Myr-p110 and Rh30-Myr-p110 $\delta$ cells up to $10 \mu \mathrm{mol} / \mathrm{L}$ (Figure 2). These results demonstrated the selectivity of A66 against PI3Ka is at the cellular level, which is consistent with results obtained in kinase assays. Similarly, TGX221 (PI3K $\beta$ ), AS604850 (PI3Kү), and CAL-101 (PI3Kס) displayed corresponding selectivity against PI3K isoforms (Figure 2). These results indicated that PI3K activity was dependent on one isoform in this panel of cells under serum-free cultural condition, and Rh30-Myr-p110 series cells could be used to identify the isoform selectivity of PI3K inhibitors at the cellular level.

\section{WJD008 was a pan-PI3K inhibitor}

WJD008 has been reported as a potent dual PI3K/mTOR inhibitor by our laboratory ${ }^{[20]}$; however, its selectivity among class I PI3K isoforms has not been studied. WJD008 was designed based on the structure of a PI3Ka-tendentious inhibitor PI-103. Accordingly, we found that WJD008 preferentially blocked Akt phosphorylation at both S473 and T308 in Rh30Myr-p110a cells at $0.37 \mu \mathrm{mol} / \mathrm{L}$ (Figure 3). A higher concentration of WJD008 $(1.1 \mu \mathrm{mol} / \mathrm{L})$ was required to reduce Akt phosphorylation in Rh30-Myr-p110 $/ \gamma$ cells. WJD008 was able to completely abrogate Akt phosphorylation in all cells of this panel at the concentration of $10 \mu \mathrm{mol} / \mathrm{L}$ (Figure 3). Although WJD008 tended to inhibit PI3Ka at lower concentration, the selective window is limited, and WJD008 blocked PI3K signaling of all four isoforms at pharmacological concentration range ${ }^{[20]}$. Therefore, WJD008 was identified as a panPI3K inhibitor. 


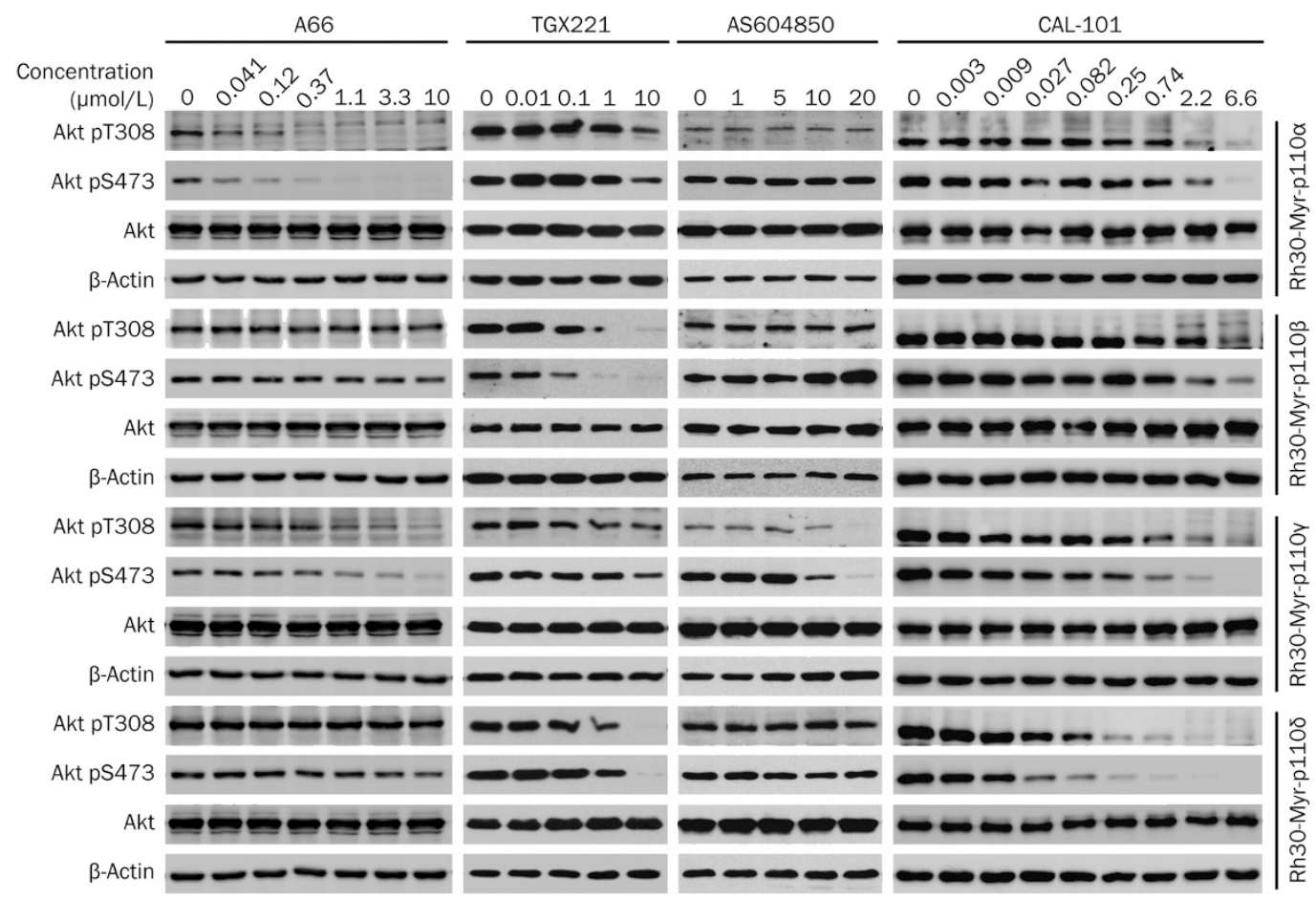

B
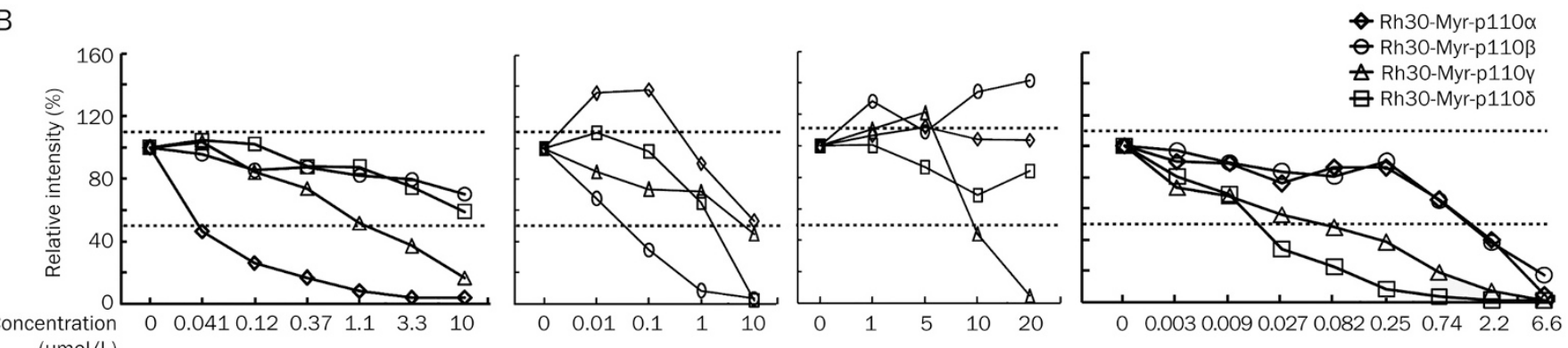
$(\mu \mathrm{mol} / \mathrm{L})$

Figure 2. Isoform-selective PI3K inhibitors blocked PI3K signaling in corresponding Rh30-Myr-p110 cells. Rh30-Myr-p110s cells were cultured in serum-free medium for $12 \mathrm{~h}$, and then exposed to the compounds at indicated concentrations for additional $1 \mathrm{~h}$. (A) The cells were collected to detect the level of phosphorylated and total Akt. B-Actin was served as loading control. (B) Relative intensity of Akt pS473 bands which was normalized to corresponding total Akt was plotted, where control was set as $100 \%$. Representative images and plots were presented.

Antitumor activity of isoform-selective and pan-PI3K inhibitors

As PI3K isoforms express differentially in different tissues, PI3K inhibitors with distinct selectivity profiles may act differently against tumors that originated from different tissues. We detected expression of the PI3K isoforms in human prostate cancer PC-3 cells and in human B cell type leukemia Raji cells. As shown in Figure 4A, relative to PC-3, p110y and p1106 were the major isoforms expressed in Raji cells. p110a and $\mathrm{p} 110 \beta$ were also detectable, whereas only p110a and p110 $\beta$ were detected in PC-3 cells. Both of the cell lines were PTEN negative, where Rh30 cells were employed as a positive control for PTEN. Meanwhile, Akt phosphorylation was more robust in PC-3 cells than that in Raji cells, suggesting more activated PI3K signaling (Figure 3).

We next determined the antiproliferative ability of A66, TGX221, AS604850, CAL-101, and WJD008 against PC-3 and
Raji cells at the concentrations that were sufficient to block Akt phosphorylation induced by their respective isoform(s). In PC-3 cells, specific inhibition of individual PI3K isoform barely has any inhibitory effect except that TGX221 (PI3K $\beta$ inhibitor) inhibited cell proliferation by $20 \%$. However, the inhibitory rate reached greater than $75 \%$ when all of the isoforms were blocked by WJD008. These results indicated that the functions of PI3K isoforms were redundant in PC-3 cells, and PI3K $\beta$ accounted for greater proportion (Figure $4 \mathrm{~B}$ ). Therefore, panPI3K inhibitors are required to gain better antiproliferation in PC-3 cells. The inhibitory profile was different in Raji cells; inhibition of PI3K (CAL-101) alone was sufficient to inhibit cell growth by $30 \%$, which was more potent than all other isoform-specific inhibitors, while inhibition of all four isoforms failed to enhance inhibition on cell proliferation, suggesting the dominant role of PI3K $\delta$ in PI3K activity in Raji cells (Figure 
A

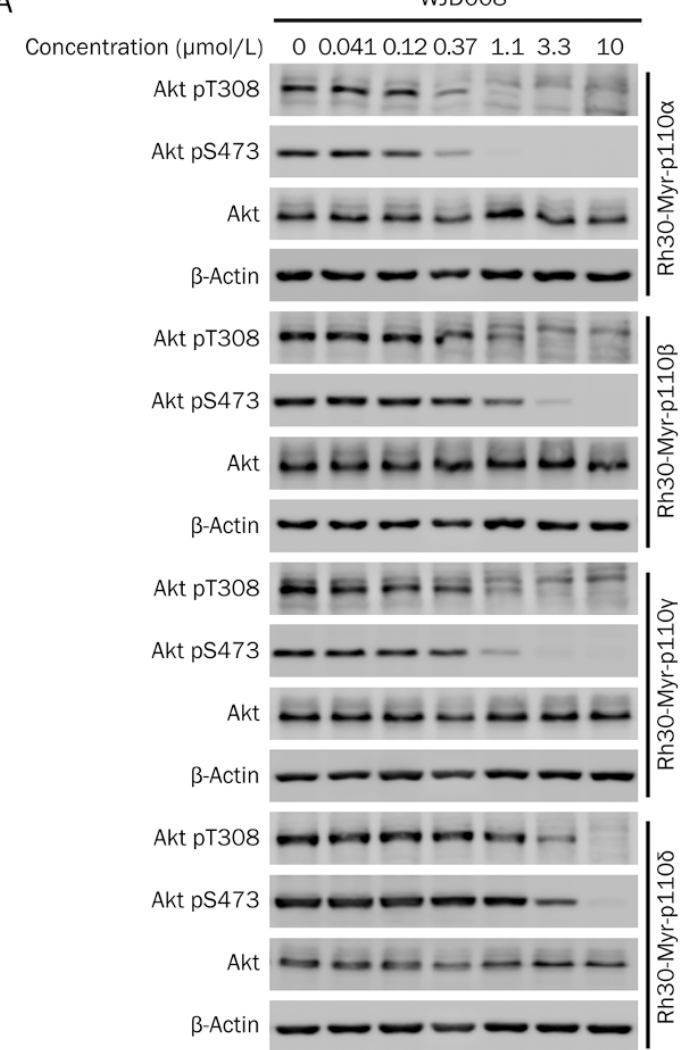

B

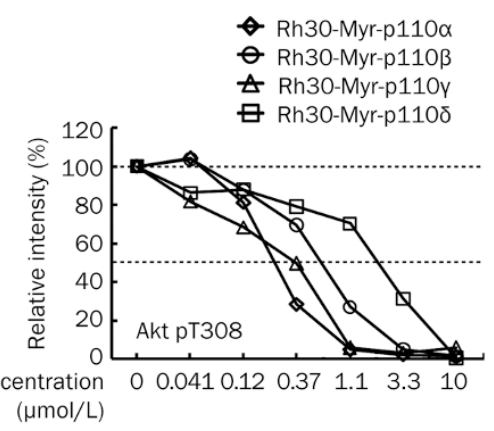

C

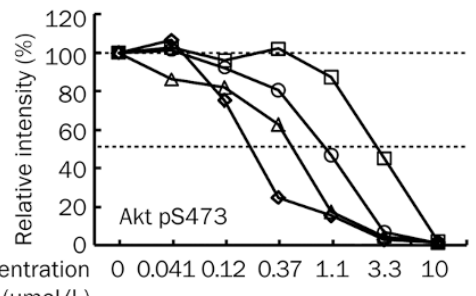

$(\mu \mathrm{mol} / \mathrm{L})$

Figure 3. WJD008 was a pan-PI3K inhibitor. Rh30-Myr-p110 cells were cultured in serum-free medium for $12 \mathrm{~h}$, and then exposed to serial diluted WJD008 for additional $1 \mathrm{~h}$. (A) Cells were collected for Western blot to analyze the level of indicated proteins. $\beta$-Actin was served as loading control. Relative intensity of Akt pT308 (B) and pS473 (C) bands which was normalized to corresponding total Akt was plotted, where control was set as $100 \%$. Representative images and plots were presented.

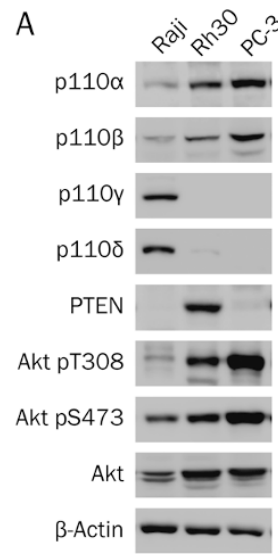

B

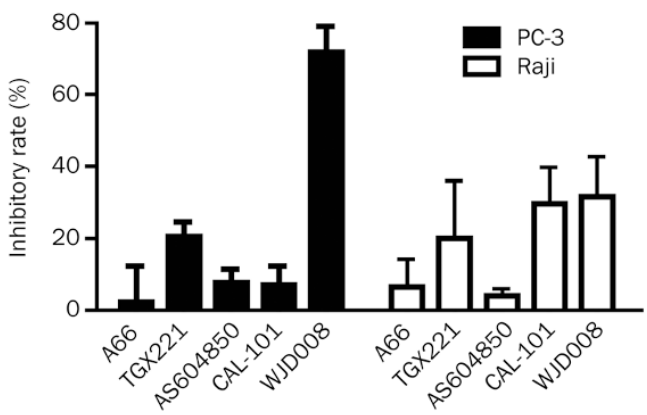

Figure 4. Antitumor activity of isoform selectivity and pan-PI3K inhibitors against cells expressing different PI3K isoforms. (A) Exponentially growing Raji, Rh30 and PC-3 cells were harvested for Western blot to detect the level of indicated proteins. Rh30 cells were used as a positive control for PTEN

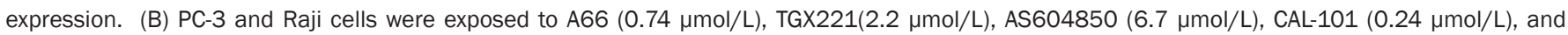
WJD008 $(10 \mu \mathrm{mol} / \mathrm{L})$ respectively for $72 \mathrm{~h}$. Cell growth was determined using SRB assay (PC-3 cells) or CCK-8 assay (Raji cells) and inhibitory rate was calculated. Data shown were mean \pm SD of at least 3 repeats.

4B). It should be noted that WJD008 was more active in inhibiting proliferation of PC-3 cells than that of Raji cells, which was most likely due to more activated PI3K signaling and the dependence of cell proliferation on PI3K in PC-3 cells than in Raji cells (Figure 4A). 


\section{Discussion}

In this study, we established a useful cell model to identify the selectivity of PI3K inhibitors among four isoforms of class I PI3K and found that a newly discovered PI3K inhibitor WJD008 was a pan-PI3K inhibitor. Using four isoform-specific inhibitors and WJD008 as probes, we revealed different dependency on PI3K isoforms for cell growth in different types of cells, where PI3K isoforms functioned redundantly in PC-3 cells and PI3K $\delta$ dominated PI3K activity in Raji cells.

Identifying the isoform selectivity of PI3K inhibitors is important for the discovery and development of drugs targeting PI3K, thus helping to predict their efficacy and toxicity in treatment of a particular tumor type. Though isoform selectivity of PI3K inhibitors could be determined with kinase assays, their activity at the cellular cell level is affected at least by ATP concentration and protein distribution. To our knowledge, this is the first time that an isogenic cellular model was provided to identify selectivity among all class I PI3K isoforms, which is unique from previous studies where different cell types and stimulators were used to measure PI3K activity ${ }^{[21,22]}$. Because it is difficult to measure PIP3 level at the cellular level, we detected the level of phosphorylated Akt as a surrogate reader for the PI3K activity, which faithfully reflects the activity of PI3K and is easily quantified. Moreover, PI3K activity was dependent on one isoform in Rh30-Myr-p110 cells under serum-free cultural condition, which avoided possible discrepancies caused by using different stimulants to trigger isoformspecific activity. Therefore, parallel comparison of activity among isoforms in cells could be fulfilled using this panel of cells, which is suitable for further optimization to meet the need of screening and validating PI3K isoform-selective compounds.

WJD008 was modified from PI-103, which is a potent, ATPcompetitive PI3K inhibitor of PI3Ka, PI3Kס, PI3K $\beta$, and PI3KY with $\mathrm{IC}_{50} \mathrm{~S}$ of $8,48,88$, and $150 \mathrm{nmol} / \mathrm{L}$, respectively ${ }^{[23,24]}$. Interestingly, WJD008 also possessed mild selectivity against PI3Ka in cells (Rh30-Myr-p110). We previously reported that WJD008 abrogated IGF-1-induced Akt phosphorylation in Rh30 cells at $1 \mu \mathrm{mol} / \mathrm{L}$, which was also sufficient to reduce myr-p110a/ $\beta$-triggered Akt phosphorylation, suggesting the similar sensitivity between ectopic p110 proteins and endogenous PI3K ${ }^{[20]}$. In biochemical assays, TGX221 was reported to inhibit PI3K $\beta$, PI3K , and PI3Ka with $\mathrm{IC}_{50}$ of $8.5,211$, and $>1000 \mathrm{nmol} / \mathrm{L}$, respectively ${ }^{[25]}$. Consistently, we found that TGX221 possessed marginal effect on PI3Ka-medicated Akt phosphorylation, whereas it displayed significant activity against PI3K $\beta$ and PI3K $\delta$, with a selectivity window of less than 10-fold (Figure 2). This limited window may result in inhibition of both PI3K $\beta$ and PI3K $\delta$ by TGX221 in Raji cells at the concentration that substantially inhibited PI3K $\delta$, which may explain the superior antiproliferative activity of TGX221 over A66 and AS604850 against Raji cells. Prostate cancer PC-3 cells are PTEN negative and express PI3Ka/ $\beta$, but not $\mathrm{PI} 3 \mathrm{~K} Y / \delta$. TGX221 was more active than A66 in inhibition of PC-3 cells, suggesting the relative dominant role of PI3K $\beta$ in this type of tumor, which is consistent with previous study ${ }^{[22]}$.
Understanding the functions of PI3K isoforms is attributed greatly to genetic approaches. However, those approaches have limitations. For example, knockout of either PI3Ka or PI3K $\beta$ led to embryonic lethality in mice. There are several advantages to utilizing small molecule compounds as probes to explore the contribution of PI3K isoforms to tumor cell growth: first, chemicals are able to specifically inhibit one or several nodal proteins; second, chemicals are able to modulate the signaling transduction in a dose- or time-dependent manner, and this modulation is reversible; and third, previous studies indicated that inactivation of target proteins with genetic approaches is not identical to inhibition by chemicals. Using PI3K isoform-selective inhibitors and pan-PI3K inhibitor WJD008, we revealed the differences in reliance on PI3K isoforms for cell growth in PC-3 and Raji cells, which are both PTEN negative and PI3K constitutively active. It also has been reported that A66 alone was sufficient to inhibit PI3Kadependent growth of SK-OV-3 tumor xenograft and that PI3K $\beta$ inhibition was critical to cease growth of PC-3 tumor xenograft, providing in vivo evidence of differences in reliance on PI3K isoforms for tumor growth ${ }^{[6,26]}$. These results rationalize determining expression level of various isoform-specific PI3K in cancer tissues in the development of PI3K inhibitors and using PI3K inhibitors with different selectivity based on the dependence of cell growth on PI3K isoform(s). Though PI3K isoforms' expressional pattern and mutational status of tumors impact their sensitivity toward PI3K targeting, it should be noted that inhibition of PI3K activity alone may not achieve complete block of cell growth (inhibition of 75\% for PC-3 cells and 30\% for Raji cells in this study), indicating PI3K-independent cell growth. Thus, combinatorial therapies are required to enhance antitumor activity of PI3K inhibitors. We attempted an in vivo study with WJD008, but its activity was not significant due to poor oral availability.

In summary, the present study demonstrated the feasibility of identifying PI3K isoform-specific inhibitors using a panel of Myr-p110 expressing cells and uncovered the biased contribution of individual PI3K isoforms for the proliferation of tumor cells, which sheds light on personalized therapy with different PI3K inhibitors.

\section{Acknowledgements}

This work was supported by the National Science \& Technology Major Project "Key New Drug Creation and Manufacturing Program" (No 2012ZX09301-001), the National Natural Science Foundation of China (№ 81021062, 81173079) and the Knowledge Innovation Program of Chinese Academy of Sciences (KSCX2-EW-Q-3). The authors gratefully thank Robert A WEINBERG (Whitehead Institute for Biomedical Research), Thomas ROBERTS (Harvard Medical School) and Peter K VOGT (The Scripps Research Institute) for sharing the plasmids and Chun-hao YANG (Shanghai Institute of Materia Medica) for providing compound WJD008.

\section{Author contribution}

Xiang WANG, Jia-peng LI, and Ling-hua MENG designed 
the research; Xiang WANG, Jia-peng LI, and Yan YANG performed the experiments; Xiang WANG, Jia-peng LI analyzed data; and Xiang WANG, Jia-peng LI, Ling-hua MENG, and Jian DING assisted with data interpretation and manuscript writing.

\section{References}

1 Braccini L, Ciraolo E, Martini M, Pirali T, Germena G, Rolfo K, et al. $\mathrm{PI} 3 \mathrm{~K}$ keeps the balance between metabolism and cancer. Adv Biol Regul 2012; 52: 389-405.

2 Hemmings BA, Restuccia DF. PI3K-PKB/Akt pathway. Cold Spring Harb Perspect Biol 2012; 4: a011189.

3 Zhu W, Nelson CM. PI3K signaling in the regulation of branching morphogenesis. Biosystems 2012; 109: 403-11.

4 Gratacap MP, Guillermet-Guibert J, Martin V, Chicanne G, Tronchere $\mathrm{H}$, Gaits-lacovoni F, et al. Regulation and roles of PI3Kbeta, a major actor in platelet signaling and functions. Adv Enzyme Regul 2011; 51: 106-16.

5 So L, Fruman DA. PI3K signalling in B- and T-lymphocytes: new developments and therapeutic advances. Biochem J 2012; 442: 465-81.

6 Jamieson S, Flanagan JU, Kolekar S, Buchanan C, Kendall JD, Lee WJ, et al. A drug targeting only p110alpha can block phosphoinositide 3-kinase signalling and tumour growth in certain cell types. Biochem J 2011; 438: 53-62.

7 Pal I, Mandal M. PI3K and Akt as molecular targets for cancer therapy: current clinical outcomes. Acta Pharmacol Sin 2012; 33: 1441-58.

8 Sadeghi N, Gerber DE. Targeting the PI3K pathway for cancer therapy. Future Med Chem 2012; 4: 1153-69.

9 Lu L, Tang D, Wang L, Huang LQ, Jiang GS, Xiao XY, et al. Gambogic acid inhibits TNF-alpha-induced invasion of human prostate cancer PC3 cells in vitro through PI3K/Akt and NF-kappaB signaling pathways. Acta Pharmacol Sin 2012; 33: 531-41.

10 Workman P, Clarke PA, Raynaud FI, van Montfort RL. Drugging the PI3 kinome: from chemical tools to drugs in the clinic. Cancer Res 2010; 70: 2146-57.

11 Sturgeon SA, Jones C, Angus JA, Wright CE. Advantages of a selective beta-isoform phosphoinositide 3-kinase antagonist, an antithrombotic agent devoid of other cardiovascular actions in the rat. Eur J Pharmacol 2008; 587: 209-15.

12 Camps M, Ruckle T, Ji H, Ardissone V, Rintelen F, Shaw J, et al. Blockade of PI3Kgamma suppresses joint inflammation and damage in mouse models of rheumatoid arthritis. Nat Med 2005; 11: 936-43.
13 Lin TS. New agents in chronic lymphocytic leukemia. Curr Hematol Malig Rep 2010; 5: 29-34.

14 Kong DX, Yamori T. ZSTK474, a novel phosphatidylinositol 3-kinase inhibitor identified using the JFCR39 drug discovery system. Acta Pharmacol Sin 2010; 31: 1189-97.

15 Dy GK. Emerging systemic therapeutic approaches for personalized medicine in squamous cell carcinoma of the lung. J Cancer Sci Ther 2012; S11:003. doi:10.4172/1948-5956.S11-003

16 Ni J, Liu Q, Xie S, Carlson C, Von T, Vogel K, et al. Functional characterization of an isoform-selective inhibitor of PI3K-p110beta as a potential anticancer agent. Cancer Discov 2012; 2: 425-33.

17 Ikeda H, Hideshima T, Fulciniti M, Perrone G, Miura N, Yasui H, et al. $\mathrm{PI} 3 \mathrm{~K} / \mathrm{p} 110\{$ delta\} is a novel therapeutic target in multiple myeloma. Blood 2010; 116: 1460-8.

18 Herman SE, Gordon AL, Wagner AJ, Heerema NA, Zhao W, Flynn JM, et al. Phosphatidylinositol 3-kinase-delta inhibitor CAL-101 shows promising preclinical activity in chronic lymphocytic leukemia by antagonizing intrinsic and extrinsic cellular survival signals. Blood 2010; 116: 2078-88.

19 Subramaniam PS, Whye DW, Efimenko E, Chen J, Tosello V, De Keersmaecker $\mathrm{K}$, et al. Targeting nonclassical oncogenes for therapy in T-ALL. Cancer Cell 2012; 21: 459-72.

20 Li T, Wang J, Wang X, Yang N, Chen SM, Tong LJ, et al. WJD008, a dual phosphatidylinositol 3-kinase $(\mathrm{P} \mid 3 \mathrm{~K}) /$ mammalian target of rapamycin inhibitor, prevents PI3K signaling and inhibits the proliferation of transformed cells with oncogenic PI3K mutant. J Pharmacol Exp Ther 2010; 334: 830-8.

21 Williams O, Houseman BT, Kunkel EJ, Aizenstein B, Hoffman R, Knight $Z A$, et al. Discovery of dual inhibitors of the immune cell PI3Ks p110delta and p110gamma: a prototype for new anti-inflammatory drugs. Chem Biol 2010; 17: 123-34.

22 Jia S, Liu Z, Zhang S, Liu P, Zhang L, Lee SH, et al. Essential roles of $\mathrm{PI}(3) \mathrm{K}$-p110beta in cell growth, metabolism and tumorigenesis. Nature 2008; 454: 776-9.

23 Knight ZA, Gonzalez B, Feldman ME, Zunder ER, Goldenberg DD, Williams 0 , et al. A pharmacological map of the PI3-K family defines a role for p110alpha in insulin signaling. Cell 2006; 125: 733-47.

24 Fan QW, Knight ZA, Goldenberg DD, Yu W, Mostov KE, Stokoe D, et al. A dual PI3 kinase/mTOR inhibitor reveals emergent efficacy in glioma. Cancer Cell 2006; 9: 341-9.

25 Chaussade C, Rewcastle GW, Kendall JD, Denny WA, Cho K, Gronning $\mathrm{LM}$, et al. Evidence for functional redundancy of class IA PI3K isoforms in insulin signalling. Biochem J 2007; 404: 449-58.

26 Edgar KA, Wallin JJ, Berry M, Lee LB, Prior WW, Sampath D, et al. Isoform-specific phosphoinositide 3-kinase inhibitors exert distinct effects in solid tumors. Cancer Res 2010; 70: 1164-72. 